\title{
THE MONEY DEMAND FUNCTIONS IN ISLAMIC ECONOMY: NEW EVIDENCE FROM IRAN-ARDL APPROACH
}

\author{
Farzaneh Sadeghi ${ }^{1}$ and Saeed Khadivy Rofougar ${ }^{2}$ \\ ${ }^{1}$ University of Applied Sciences, Mashhad Municipality, Mashhad, Iran. \\ Email: farzaneh.sadeqi@gmail.com \\ ${ }^{2}$ ACECR Institute of Tourism Research, Mashhad, Iran. Email: khadivy@gmail.com
}

\begin{abstract}
The demand for money is one of the most fundamental issues of the monetary economy for policy decision. However, according to the principle of prohibition of Riba, attitudes about the money market conditions in Islamic economics, is quite different from conventional economics. Therefore, effective functioning of money demand in an Islamic country would be necessary. Most studies about the money demand in Islamic economy used the Keynesian approach, while in modern macroeconomics, money demand function is drawn upon using the microeconomics-based approach. Thus, this article first investigates some models of the microeconomics-based approach, and then, in accordance with Islamic principles, chooses shopping-time model as the best among them. Next, we derive the Islamic money demand function. The results indicate that the demand for money is the function of income and rental rates of sukuk. The marginal product of capital due to an additional unit of income spend for Infaq (spending in Allah's way), depend on the expected inflation rate, depreciation rate and rental rates of Sukuk. In this paper, we apply ARDL approach to estimate the money demand function in Islamic republic of Iran in period of 1978-2008 i.e. after Islamic revolution. The results suggested that M1 and M2 money demand are co-integrated with income and rental rate of Sukuk. Incorporating CUSUM and CUSUMSQ tests into co-integration analysis, we conclude that M2 money demand is more stable than M1.
\end{abstract}

Keywords: Money Demand; Shopping- Time Model; Islamic Economy; ARDL Approach; Iran. JEL Classification: E41; P44; C32.

Received : August 13, 2018

Revised : October 08, 2018

Accepted : November 29, 2018 


\section{INTRODUCTION}

The topic of demand for money is of key and pivotal issues in monetary and income determination theories, which has attracted the attention of many economists. Such attention has led to the theory of money demand to experience many changes over time and contain a rich literature.

On the other hand, the money and its market in Islamic economics literature, due to the prohibition of Riba and direct opposition of Islam with interest rate, have a special and privileged status. In the meantime, the topic of money demand in Islamic economy due to being influenced by moral principles has been of particular importance.

In the past years, there have always been various models of money demand function, introduced in the Islamic economic system. However, in presenting money demand function for Islamic economics, compared to conventional literature of money demand, there have unfortunately been some drawbacks. In the provision of these models, little concern is given to modern macroeconomics and its differences with the traditional macroeconomic. Even the models that have been made with respect to this matter have neither entirely investigated the new literature of money demand, nor mentioned how to choose the specific model for money demand function in Islamic economics. Consequently, providing a model for the money demand in Islamic economy based on new theories in conventional economics and reviewing the capabilities of the offered model in accordance with the Islamic requirements are necessary.

That said, in this study we intend to review the proposed models for money demand in Islamic economy, pay attention to the positive and negative aspects of these models, and finally, with the introduction of modern money demand models in conventional economics based on the micro foundations for money demand, show their strengths and weaknesses. Then, by choosing one of the models, we present money demand function in Islamic economy based on Islamic principles and in the theoretical frameworks of this model. Finally, in order to investigate the long-run relationship among the variables in the models, ARDL approach developed by Pesaran and Shin (1999) has been employed.

\section{LITERATURE REVIEW}

Because of the importance of money and its nature in Islam and their important role in the economic policies of Islamic countries, numerous studies regarding demand for money in Islamic economics have been conducted, each of which picked a certain perspective toward this phenomenon, reviewed, and discussed it. Finally, they have derived money demand function for Islamic economic system or interest-free economic system. This view can be divided into two categories for Iran:

In the first method, Muslim economists have often studied demand for money in Islamic economics with the Keynesian theory, i.e., they divide money demand in terms of its motives and the role of money in the economy in general and analyze each one, thoroughly. We can highlight Latif (1990) who first categorized money demand to demand for livelihood and charity cases, and obligatory and recommended issues, illuminating the direct function of income and inflation and 
money demand to earn income which consists of money demand for investing and for transactions (commerce) that is a function of the rate of return. After stressing the condemnation of interest and speculation, he extracts Islamic money demand functions.

In addition, Mir Moezi (2003) derives money demand in Islamic economics in the midst of disagreement by many Muslim economists concerning money demand. He considers the origin of this dispute, the function of money as a store of value in its Keynesian concept. Therefore, he reviews and criticizes Muslim economists' ideas about the function of store of value, the permit of money by Kenz in its economic terms, and the permit for speculation in the framework of religious law. He concludes that money holding with the intention of speculation is permissible under the religious law. In so doing, he claims that in Islamic economics, there is the demand for money with speculation motive. Then, he presents his intended theory, first from a micro and then from a macro perspective. However, as he himself asserts, this theory of money demand is drawn upon the Keynesian approach in the conventional economics.

Finally, in this category of studies, we could pinpoint the research of Esmaili, et al. (2012) conducted jointly, and review the demand for money in a non-Riba economy. They acknowledge the fact that the roles of money and a variety of its demand are well known in the economies with Riba. In addition, they consider what remains uncertain: the existence of the same roles and demands in the nonRiba economy due to the lack of loan market. In this paper, first, financial assets market is introduced and shown that the same information that money market presents in an economy with Riba, the loan market, creates when removing the aforementioned market. It is shown that this activity is carried out on the basis of its general or specific conditions in emerging financial markets. However, there are possibilities of speculation for financial assets. If the rules of Islamic contracts to carry out long-term contracts in the aforementioned are observed and stabilization policies of economic conditions are adopted by central bank, the aforementioned conditions will disappear, and the field of speculation in the asset market will disappear. In this case, the speculative demand for money does not form. Using the data from the property market, and in the absence of a market for loans, money demand function is derived and estimated. Results of this function evaluation, using co-integration of maximum likelihood of Johansen-Juselius procedure show that a significant and stable relationship between independent variables and money demand.

As for the second category that does not have a large range among Muslim economists, studies have attempted using a microeconomic approach to heed the money demand, including Moradi (2000), who derived and designed the money demand in an interest-free economy using the Cash-in-Advance model (Clover). This model, however, is not an Islamic money demand model, but it is built based on assumptions of economies of Islamic countries that their banking system is based on interest-free banking. Moreover, in these economy systems, bonds have little role in the economy. Moradi has then derived and tested money demand function. Further, Rezaei and Moghaddam (2012), in an article presented money in the utility function in the Islamic economic system using an optimal control model, distinguish its differences with conventional economics while discussing 
the characteristics of money in the Islamic economic system. They claim that in Islamic economy, the element of money for a Muslim, by reducing transaction costs, and the possibility of achieving nearness of God through the material and spiritual payments is followed by utility. They finally introduce three variables of money, consumption expenditures, and charity in the form of a optimal control pattern into the utility function, and conclude that in the stationary condition: a) the marginal product of capital is equal to the rate of time preference; b) the marginal utility caused by consumption is equal to marginal utility caused by charity; and c) the marginal rate of substitution between money and consumption is equal to the opportunity cost of holding money. Finally, neutrality and super neutrality of money, and lack of these two features depend on the structure of the utility function.

Ultimately, Kia (2003) reviews the stability of money demand in the interestfree economy, with emphasis on the role of agents. He derives money demand function for an interest-free economic system using foundations of micro models. By using data from Iran, the study proves the stability of money demand models in the interest-free economy.

Today in macroeconomics, derivation of money demand models using the micro foundations are of greater interest. Thus, this study intends to use this approach to achieve the money demand in Islamic economy. The interesting point is that the difference of this research with other studies on money demand with micro approach is that in the latest studies, the researchers sought to provide money demand in an interest-free economy; and therefore, the only key difference of these models with conventional money demand models is just removing the interest rate.

In the study by Rezai (2012) in creating money demand function from an Islamic perspective, a technique is used which according to Islamic principles was wrong to consider, and therefore, this study will seek to correct this approach. In the following discussion, while presenting a money demand micro models in conventional economies, we will discuss their capability in providing money demand models, from an Islamic perspective.

\subsection{Microeconomics Approach to Money Demand (Selecting Accurate Model)}

The neoclassical growth model is a model of a nonmonetary economy, and to employ the neoclassical framework to analyze monetary issues, a role for money must be specified in order for the agents to hold positive quantities of money. A positive demand for money is necessary if, in equilibrium, money is to have positive value (Walsh, 2010). There are different approaches for optimizing of consume and production by agent (households and firms). Three general approaches to incorporating money into general equilibrium models are followed (Walsh, 2010):

1) Assume that money yields direct utility by incorporating money balances into the utility functions of the agents of the model (Sidrauski, 1967);

2) Impose transaction costs of some form that give rise to a demand for money by making asset exchanges costly (Baumol, 1952; Tobin, 1956), requiring that money be used for certain types of transactions (Clower, 1967), assuming that time and money can be combined to produce transaction services that 
are necessary for obtaining consumption goods (Brock, 1974; McCallum and Goodfriend 1987; Croushore, 1993), or assuming that direct barter of commodities is costly (Kiyotaki and Wright, 1989);

3) Treat money like any other asset used to transfer resources inter-temporally (Samuelson, 1958).

The money-in the-utility function (MIU) model is originally due to Sidrauski (1967) and has been used widely. It can be employed to examine some of the critical issues in monetary economics - the relationship between money and prices, the effects of inflation on equilibrium, and the optimal rate of inflation. To understand better the role of money in such a framework, a linear approximation is presented in Handa (2009).

It is believed that the demand for money is instrumental in that we hold money to engage in transactions leading to the purchase of the goods and services that actually yield utility, while at the same time, reflecting on the money-in-utility function assumption, we argue that money balances yield utility before going to purchase consumption goods (Walsh, 2010). In other words, although most of economists believe that money do not have usage inherently and its function is just in facilitating transactions that creates valuable services and therefore money can enter into the utility function, but in this model, the proposition is reverse.

Further, the major criticism arrives at this model. Assuming that holdings of real money balances yield direct utility, it is a means of ensuring a positive demand for money. Consequently, in equilibrium money is held and has value. This assumption is clearly a shortcut, as it does not address the issue of why money yields utility or why certain pieces of paper that we call money, and why it yields utility but other pieces of paper presumably do not.

It seems that this model is not valuable for Islamic economics; because the utility of holding money is considered in itself inherently. This model assumed that holding money by itself and regardless of the application and its function in the economy has utility for the consumer. Even if we accept the utility and psychological impact for the money, which means that, as the above analysis, regardless of accelerating transactions and enabling the purchase of goods and services available, the holding of money for individual is desirable.

According to the Holy Quran statements, ayah (verses) 34 and 35 of Surah At-Tawbah (The Repentance) give the command to honor Kanz (treasure) and verses 2 and 3 Surah of Al-Humazah (The Traducer) blame people who have some characteristics, such as love of money and property adoration. Islam does not accept this kind of utility of money in any way. Therefore, based on these conditions this model could not be used in explaining the demand for money in Islamic economics. To put it simply, money by itself and regardless of the application and its function could not be used directly in the utility function of a Muslim.

A direct approach for generating a role for money, proposed by Clower (1967) and developed formally by Grandmont and Younes (1972) and Lucas (1980a), captures the role of money as a medium of exchange by requiring explicitly that money be used to purchase goods. Such a requirement can also be viewed as replacing the substitution possibilities between time and money highlighted in the shopping-time model with a transaction technology, in which shopping time 
is zero if $M / P>=C$ and infinite otherwise (McCallum, 1990a). This specification can be represented by assuming that the individual faces, in addition to a standard budget constraint, a cash-in advance (CIA) constraint. The exact form of the CIA constraint depends on which transactions or purchases are subject to the CIA requirements. For example, both consumption goods and investment goods might be subject to the requirement. Or only consumption might be subject to the constraint. Or only a subset of all consumption goods may require cash for their purchase. The constraint will also depend on what constitutes cash. (Walsh, 2011).

Taking two markets of assets and product, CIA constraint assumes that depending on which market opens faster, the individual faces two different modes: in the mode of fast opening of the asset market, the individual can convert its assets into cash and spend it in the consumer market. Otherwise, the individual only considers the amount of money from previous period for expenditure. To put it simply, in this constraint, the income from production during the period $t$ to $t_{+1}$ will not be available.

Although the popularity of pre-liquidity approach, is due to it being an easy way to inject money into the dynamic macroeconomic framework, it is not recommended with regard to pre-liquidity constraint in this model for Islamic economics. Another reason is associated with the second constraint, in that it uses the fixed interest rate is formed with regard to the relationship between certain commodity and asset markets, despite the fact that the relationship between these two markets in the Islamic economics is very complicated. Thus, although not completely rejected in Islamic economics, but due to much complexity of the basic constraint, this model is not recommended to be utilized in Islamic economics.

Another direct approach to modeling the role of money in facilitating transactions is to assume that the purchase of goods requires the input of transaction services. First, a model is considered in which these services are produced using inputs of money and time presented in McCallum and Goodfriend (1987). When transaction services are produced by time and money, the consumer must balance the opportunity cost of holding money against the value of leisure in deciding how to combine time and money to purchase consumption goods. The production technology used to produce transaction services determines how much time must be spent "shopping" for given levels of consumption and money holdings. Higher levels of money holdings reduce the time needed for shopping, thereby increasing the individual agent's leisure. (Walsh, 2011:92).

Finally, Samuelson (1985) introduces the concept of overlapping generations for the analysis of money in the economy. Such models are the dynamic equilibrium models that rely on the difference in saving between young and old. However, the basic OLG model assumes that there are no other assets such as bonds, which can act as a store of value function with a higher rate of return than on fiat money. It does not really act as a medium of exchange in those transactions in which saving is not an integral part of the transaction as intended by either party. Additionally, it is this role that is essential to the nature of money in the modern economy. The standard version of the OLG model assumes that the individuals in the economy live for two periods only - or for two life-stages, "young" and "old," with each lifestage lasting one period - and that in each period the economy has two generations of individuals, one being the old generation of individuals who were born in the 
preceding period and the other the young generation born at the beginning of the current period. The subsequent old and young generation could overlap in every period. Each individual is assumed to be given a commodity endowment of $\left(\mathrm{w}_{\mathrm{y}}\right)$ in the young life-stage and $\left(\mathrm{w}_{\mathrm{o}}\right)$ in the old life-stage, that they are in units of the single consumption good, assuming in the basic model to be non-storable (perishable), and assuming that $\left(\mathrm{w}_{\mathrm{o}}\right)$ is zero. It does not exist any type of savings instrument. In this case, the assets are tradable only with money and then can be stored (Handa, 2009).

The important point in this model, which weakens its utilization in money demand in Islamic economy, is that this model emphasizes the money value of store and not the exchange interface. It is notable that in the Islamic economics, firstly, there is not a consensus over the store of value of money, and secondly, if a store of value for money in Islamic economics is accepted, it is due to acceptance of its exchange value. It means that experts argue in accepting the money value of the store is in its correlation of functions. Evidently, because money is a medium of exchange, it necessarily should be the means of the store of value.

To put it simply, money in Islamic economics, money in itself, and in its essence, is not capable of being the store of value. Finally, by examining the economic conditions of some countries with high inflation, including Iran, we see that this assumption does not comply with the characteristics of these countries, and money in the current economic conditions of most of these countries, has maintained the role of being a store of value in a very weakly manner.

By investigating the shopping time model, we specify that this model does not have the basic weaknesses that another models have in order to be used in money demand function in Islamic economics. Thus, we apply this model in our study.

\section{METHODOLOGY}

\subsection{Introduction of Islamic Money Demand Function}

As previously described, the best model in modern macroeconomics that can be used to make money demand function in Islamic economics is the shopping time model. Unlike the other models, this model does not have the basic weaknesses in order to be used in money demand function in Islamic economics. At present we attempt to develop an appropriate function form for the Islamic money demand model. In this regard, we maximize the appropriate utility function, which has a certain form and indicates fewer assumptions on the consumer's behavior by indicating the budget in accordance with the Islamic foundations, from which demand function is resulted.

Based on the principles outlined in the shopping time model of McCallum and Goodfriend (1987), analysis is conducted using the budget constraint and a public utility function that measures the spending and the time of the purchase and maximize the utility function, all of which direct to a money demand relationship to estimate.

Given a hypothetical households, utility function will be as follows:

$$
U_{t}=U\left(\mathrm{c}_{t}, 1_{t}\right)
$$


$\mathrm{C}_{\mathrm{t}}$ is the household spending, and $l_{t}=1-s_{t}$ is the household leisure time, which is located in the utility function. $S_{t}$ is also the time of purchase. This is the utility function, which is generally consistent with Islamic foundations and does not contradict them.

Since the time of purchase is a function of $\mathrm{m}$ and $\mathrm{C}$; therefore, the leisure time function would be as follows:

$$
L_{t}=L\left(\mathrm{c}_{t}, m_{t}\right)
$$

In order to offer a solution for the amounts of money demand, a mathematical function form for the utility should be introduced. Not unlike Apergis, et al. (1999), specific function form of the utility function is considered as the CobbDouglas function, described subsequently. Moreover, the leisure time function is also embedded in the same way. Where $0<\mathrm{a}<1$ and $0<\mathrm{b}<1$ :

$$
\begin{aligned}
& U\left(\mathrm{c}_{t}, \mathrm{l}_{t}\right)=c_{t}^{1-a} l_{t}^{a} \\
& L\left(\mathrm{c}_{t}, m_{t}\right)=c_{t}^{-b} m_{t}^{b}
\end{aligned}
$$

In this case, the utility function is resulted from a combination of the two functions as follows:

$$
\mathrm{U}\left(\mathrm{c}_{t}, m_{t}\right)=c_{t}^{1-a-b} m_{t}^{a b}
$$

Such utility function is indicative of the dynamic of the intended model. Our hypothetical household maximizes its utility based on the 2 following constraints:

First constraint, which in fact, is compatible with Islamic foundations and previously was analyzed, is as follows:

$$
l_{t}=\psi\left(\mathrm{c}_{t}, m_{t}\right)
$$

The second constraint is distinction of the Islamic money demand model and McCallum and Goodfriend's model based on Islamic approach to the shopping time model. In the shopping time model, this constraint is composed of two parts: its left side containing available resources of a person at the beginning of the period, and the right side of this equation showing the individual's consumption expenditures in the period $t$.

$$
Y_{t}+\left(1+\pi_{t}\right)^{-1} \mathrm{SK}_{t-1}+(1-\delta) \mathrm{k}_{t-1}+\left(1+\pi_{t}\right)^{-1} m_{t-1}=c_{t}+g_{t}+k_{t}+\left(1+R_{t}\right)^{-1} s k_{t}+m_{t}
$$

All the elements of this constraint will be explained as follows:

There have been numerous discussions on costs and expenses of a Muslim person in Islamic economics (Ezzati, 2003; Hosseini, 2000; Iravani, 2012). In general all these studies emphasize three types of a Muslim person's expenses:

1) Consumer expenditure, which is used in order to purchase goods and services for personal consumption, which is shown here with (c). 
2) Social participation expenditure, which is used for charity, endowment, or religious dues, overall, the expenditure done to satisfy God, which are shown with the symbol $(\mathrm{g})$ in this equation.

3) Savings and investment expenditure, which is made for the purpose of investment or purchase of capital goods or savings for the future, considered with the common symbol of $\mathrm{k}$. It is worth mentioning that in this model because it is not possible for money to store its value, the difference should be considered between investment and savings from the household's perspective. Investment for earning revenue is done in future periods and placed in the production function; however, savings are used only for discretionary purchases in future periods.

In the base model for household savings, the bonds have been used, while it is obvious that in Islamic economics the bonds cannot be used. The alternative for the bonds for savings in this model is the rental Sukuk (sk). These bonds have the possibility of receiving their nominal value at the end of the period. Naturally with having the purchase option document, as well as the ability to buy and sell on the secondary market, the bonds are the suitable opportunity to save in Islamic economics. Besides, they are inclusive in this model. In this market, rental rate $\mathrm{R}$ instead of interest rate is determinant. Finally, part of the money $(\mathrm{m})$ may remain in cash, which we will use in the consumption expenditures section in this model.

However, in the resource sector, we are not faced with substantial differences from the original model. As a result, like the McCollum model, we face the income from productive activity $f\left(\mathrm{k}_{\mathrm{t}-1}\right)$, and net government transfer payments (subsidies minus taxes), as a Muslim's resources at the start of the period confirmed by the religion. In order to simplify the model in this stage, rather than neo-classical production function $f\left(\mathrm{k}_{\mathrm{t}-1}\right)$ and government transfer payments $v_{\mathrm{t}^{\prime}}$ the total income of the consumer $(\mathrm{Y})$ is used.

In addition, part of the remaining capital and cash from the previous period, can also be counted as the resources of the beginning of the new period. However, as far as resources are concerned, the interesting point is that in the Islamic economic system the remaining cash from the previous period is assigned to Khums, a fifth share, and its volume is reduced to $4 / 5$. However, because this factor has no impact in money demand function, we remove it from the model. In addition to the aforementioned items, the person can also give over the remaining Sukuk bonds from the previous period, given their maturity is reached, so long as these bonds have already been bought for the same maturity at its nominal value in the previous period and considers the proceeds from it as a source of income.

Another difference in constraint is the level of expenditure (g), according to the studies on religious expenditure by "Hosseini (2000), Ezzati (2003), and Sobhani \& Mehrbani (2007)" is charity or expenditure in order to please God. The most important factors affecting this variable are the level of income $Y$ and virtue (faith). In the model presented in this study, virtue may vary over time, as well as affect other variables such as consumption. Therefore, if we consider it as a variable, it leads to the complication of the model. Thus, for simplicity we assume that the level of virtue in Muslim people is at its highest and steadiest level. Accordingly, we assume the level of expenditure in order to please God as a function of individual income. 
There are two points worth mentioning: first, the constraint being used in McCallum model is real. This paper reflects the basis of the analysis of this study. Second, the lack of money substitutes in the model is real because this approach has a transaction view on money demand not on money as the store of value. In addition, since the money substitutes discussion is raised at the time when the money has its duty as the store of value in the economy of the country, we avoid the entrance of the money substitutes to the model.

\subsection{Solving the model}

The model solve as dynamic and over time $t$. In order to solve, we formed the following Lagrange system:

$$
\begin{aligned}
& L=\sum_{0}^{\infty} \beta^{t} \mathrm{U}\left(\mathrm{c}_{t}, m_{t}\right)+\sum_{0}^{\infty} \beta^{t} \gamma_{t}\left[Y_{t}+\left(1+\pi_{t}\right)^{-1} s k_{t-1}+(1-\delta) \mathrm{k}_{t-1}+\left(1+\pi_{t}\right)^{-1} \mathrm{~m}_{t-1}\right. \\
& \left.-c_{t}-g_{t}-k_{t}-\left(1+R_{t}\right)^{-1} s k_{t}-m_{t}\right]
\end{aligned}
$$

First order condition subject to $\mathrm{c}, \mathrm{m}, \mathrm{b}$ and $\gamma$ will be as follows:

$$
\begin{aligned}
& \beta^{t} \mathrm{U}_{C}-\beta^{t} \gamma_{t}=0 \\
& \beta^{t} \mathrm{U}_{m}-\beta^{t} \gamma_{t}+\beta^{t+1} \gamma_{t+1}\left(1+\pi_{t+1}\right)^{-1}=0 \\
& -\beta^{t} \gamma_{t}\left(1+R_{t}\right)^{-1}+\beta^{t+1} \gamma_{t+1}\left(1+\pi_{t+1}\right)^{-1}=0 \\
& -\beta^{t} \gamma_{t} \mathrm{f}^{\prime}\left(k_{t}\right)-\beta^{t} \gamma_{t} \mathrm{G}_{y}^{\prime} \mathrm{f}^{\prime}\left(k_{t}\right)+\beta^{t+1} \gamma_{t+1}(1+\delta)=0 \\
& Y_{t}+\left(1+\pi_{t}\right)^{-1} b_{t-1}+\left(1+\pi_{t}\right)^{-1} \mathrm{~m}_{t-1}-c_{t}-m_{t}-\left(1+R_{t}\right)^{-1} b_{t}=0
\end{aligned}
$$

By combination of three equations (9), (10) and (11) it can be attained that:

$$
\mathrm{U}_{m}=\mathrm{U}_{c} \frac{R_{t}}{\left(1+R_{t}\right)}
$$

Using equation (11) and (12) we have:

$$
\mathrm{G}_{y}^{\prime} \mathrm{f}^{\prime}\left(k_{t}\right)-\mathrm{f}^{\prime}\left(k_{t}\right)=\frac{\left(1+\pi_{t+1}\right)(1-\delta)}{\left(1+R_{t}\right)}
$$

The partial derivative of the utility function by using equation (5) will be as follows:

$$
\begin{aligned}
& \mathrm{U}_{c}=(1-a-a b) \mathrm{c}_{t}^{-a-a b} m_{t}^{a b} \\
& \mathrm{U}_{m}=a b c_{t}^{1-a-a b} m_{t}^{a b-1}
\end{aligned}
$$


Replacing two equations above in (14), we have:

$$
m_{t}=(a b / 1-a-a b)\left(1+\frac{1}{R_{t}}\right) \mathrm{c}_{t}
$$

Logarithm of (8) will be equal to:

$$
L \mathrm{n}\left(m_{t}\right)=\operatorname{Ln}(\mathrm{ab})-\operatorname{Ln}(1-\mathrm{a}-\mathrm{ab})+\operatorname{Ln}\left(1+\frac{1}{R_{t}}\right)+\operatorname{Ln}\left(\mathrm{c}_{t}\right)
$$

In derived relationship, we have two unknown variables, spending and money. In this case, similar population should be assumed, so derived money demand function will be for consumer society. On the other hand, according to McCallum, if we consider the assumption of full market clearing, then the total consumption will be equal to total income. As a result, we will face only one unknown variable, money demand. In this way, money demand can be introduced as a function of other variables:

$$
L \mathrm{n}\left(m_{t}\right)=a_{0}+a_{1} \operatorname{Ln}\left(y_{t}\right)+a_{2} \operatorname{Ln}\left(\mathrm{R}_{t}\right)
$$

The function is linear-logarithmic, that all variables have been entered logarithmically because the demand functions are often estimated on logarithmic form. That said, in this way money demand elasticity with respect to variables can be calculated. Another result of this relationship can be obtained from equation (15). According to it, the marginal product of capital, spending by an additional unit of income for the charity depends on expected inflation, the depreciation rate and rental rates of Sukuk.

\section{RESULTS AND DISCUSSION}

The data set used in our empirical analysis consists of annual data on several variables: real income measured by the GDP index (1997=100), prices (P) measured by CPI (1997=100), money (M) measured by Ml and M2, and rental rates of Sukuk (R) measured by the yield on short-term savings deposits with commercial banks were employed over the period 1978-2008 (30 years after the Islamic Revolution). Rental rates of Sukuk are for Sukuk al-Ijara from Money and Credit Council in Iran. Data were obtained from the annual Statistical Bulletin of Central Bank of the Islamic Republic of Iran.

Most studies conducted in money demand consider the Regressive Distributed Lag (ARDL) approach as a successful tool in the specification. Additionally, estimation of money demand function is introduced originally by Pesaran and Shin (1999) and further extended by Pesaran, et al. (2001). This framework examines the long-run equilibrium relationship for money and the variables affecting it, and their short-term volatility at the same time.

The bounds test method co-integration has certain econometric advantages in comparison to other methods of co-integration:

a) First, this approach makes a distinction between independent and explanatory variables and solves the problem of endogeneity. All variables of the model are assumed endogenous. 
b) Regardless of the degree of convergence of estimator, we attempt to identify and estimate the model, and could remove the problems of standard analysis of convergence about the same degree of convergence variables and also there is no need to unit root test. Bounds test method for co-integration is applied irrespective of the order of integration of the variable. There may be either integrated first order I (1) or I (0)

c) The short-run and long-run coefficients of the model are estimated simultaneously; and resolve the problems related to missing variables and the autocorrelation.

In the present study, in order to investigate the existence of the long-run relationship among the variables in the models, the ARDL approach developed by Pesaran et al. (2001) is employed. However, prior to estimate the behavioral coefficients of model using time series data, modern econometric methods require testing of the parameters reliability. Therefore, before testing the model, unit root tests were conducted to check the presence of unit root in variables. The results of the unit root test are presented in Table 1.

Table 1.

Results of Unit Root Test

\begin{tabular}{lcccccc}
\hline \multirow{2}{*}{ Results } & \multicolumn{3}{c}{$\mathbf{1}^{\text {st }}$ Difference } & & Level & \\
\cline { 2 - 7 } & PP & ADF & & PP* & ADF & \\
\hline $\mathrm{I}(1)$ & -1.95 & -2.92 & DLM2 & -1.95 & 1.54 & LM2 \\
$\mathrm{I}(1)$ & -2.95 & -3.81 & DLM1 & -2.95 & -2.09 & LM1 \\
$\mathrm{I}(1)$ & -1.95 & -2.97 & DLY & -1.95 & 1.74 & LY \\
$\mathrm{I}(1)$ & -1.95 & -5.07 & DLR & -1.95 & 0.94 & LR \\
$\mathrm{I}(1)$ & -2.95 & -5.38 & DLE & -2.95 & -0.2 & LE \\
\hline
\end{tabular}

* Significant at $5 \%$ significance level

According to the test statistic value and critical values presented in Table 1, it is shown that all the variables are stationary at their first difference. Therefore, co-integration test was carried out to check whether they have a meaningful co-integration relationships exist in the long-run. By considering the equations estimated by ARDL method, the pattern contains two sets; the long-run equilibrium equations and error correction model (ECM). Due to the relatively small sample size, we use Schwarz Bayesian criterion to determine the optimal lag of variables of each model.

Based on annual data and the Schwartz Bayesian criteria, one lag length for M1 and M2 and zero lag length for other variables of the money demand function were selected. Now given the short-term dynamics, long-term relationship can be tested. The results of a long-term model related to ARDL $(1,0,0,0)$ for money demand of real balances M1 and M2 shown in Tables 2 and 3 respectively. 
Table 2.

Results of The Long-Run Coefficient of M1 Money Demand Model

\begin{tabular}{lccc}
\hline $\begin{array}{l}\text { M1: Short-run } \\
\text { Estimation }\end{array}$ & Coefficient & $\begin{array}{c}\text { M1: long-run } \\
\text { Estimation }\end{array}$ & Coefficient \\
\hline$L M 1(-1)$ & 0.31 & & \\
$L Y$ & $(2.09)^{*}$ & $L Y$ & 1.009 \\
& 0.7 & & -10.3 \\
$L R$ & -4.4 & $L R$ & -0.44 \\
& -0.3 & & $(-4.7)$ \\
$C$ & $(-3.25)$ & $C$ & -0.3 \\
& -0.21 & & $(-0.295)$ \\
\hline
\end{tabular}

The long-run models can be written as follow: $\mathrm{Lm} 1=-0.3+1.009 \mathrm{Ly}-0.447 \mathrm{Lr}$

*t-test value has shown in parentheses

Table 3.

Results of The Long-Run Coefficient of M2 Money Demand Model

\begin{tabular}{lccc}
\hline $\begin{array}{l}\text { M2: Short-run } \\
\text { Estimation }\end{array}$ & Coefficient & $\begin{array}{c}\text { M2: long-run } \\
\text { Estimation }\end{array}$ & Coefficient \\
\hline$L M 1(-1)$ & 0.55 & & \\
LY & $(5.61)^{*}$ & $L Y$ & 1.82 \\
& 0.82 & & -12.57 \\
$L R$ & -5.3 & $L R$ & -0.7 \\
& -0.317 & & $(-5.8)$ \\
$C$ & $(-3.98)$ & $C$ & -8.91 \\
& -4.02 & & $(-5.66)$ \\
\hline
\end{tabular}

The long-run models can be written as follow: $L m 2=-8.91+1.82 \mathrm{Ly}-0.7 \mathrm{Lr}$

*t-test value has shown in parentheses

Specifically, the results of Short-run estimation of M1 money demand suggest that $\mathrm{t}$-statistic calculated by Banerjee test $(\mathrm{t}=(0.31-1) / 0.15=-4.6)$ is larger than the critical value provided by Banerjee, et al equal to (-2.5) at 95 percent confidence level. Such a result is also true for M2 money demand function. Then, t-statistic calculated by Banerjee test $(t=(0.55-1) / 0.097=-4.63)$ is larger than the critical value provided by Banerjee, et al equals to (-3.35) at 95 percent confidence level. Therefore, the existence of the long-run equilibrium relationship among the variables of the two models was confirmed.

The co-integration test results show that the presence of co-integration among Lr, Ly can be seen in the estimated long-run money demand function for M1 and M2. Thus, they are consistent with the previous literature that has emphasized that M1 and M2 are highly co-integrated with the logarithm of rental rate and real GDP. In addition, significant negative coefficient of real rental rate and the significant positive coefficient of real GDP in this study are also consistent. 
In order to link the short-term fluctuations and long-term balances, an error correction model is estimated. This model considers the differential values of variables, including the lagged error terms of the long-run balance relationship as the error correction term, along with the values of difference of the dependent variable. The results of the error correction model estimation for M1 and M2 are presented in Table 4.

Table 4.

Results of the Error Correction Model of M1 and M2

\begin{tabular}{lccc}
\hline M1 ECM & Coefficient & M2 ECM & Coefficient \\
\hline$D L Y$ & 0.7 & $D L Y$ & 0.82 \\
& $(4.4)^{*}$ & & -5.3 \\
$D L R$ & -0.3 & $D L R$ & -0.317 \\
& $(-3.25)$ & & $(-3.98)$ \\
$D c$ & -0.21 & $D c$ & -4.03 \\
& $(-0.296)$ & & $-5.2)$ \\
$E c m(-1)$ & -0.69 & $E c m(-1)$ & -0.45 \\
& $(-4.76)$ & & $(-4.63)$ \\
\hline
\end{tabular}

The long-run models can be written as follow: DLM $1=-0.21+0.7 \mathrm{DLy}-0.3 \mathrm{DLR}-0.69 E C M(-1)$ and DLM $2=-4.03+0.82$ DLy $0.317 D L R-0.45 E C M(-1)$

*t-test value has shown in parentheses

Evidently, the variable coefficient of ECM indicates the speed of adjustment toward the long-term balance. Significance of this factor suggests that about 69 percent of deviations of real M1 money demand from long-term balances and about 45 percent for real M2 money demand are adjusted after one period. In other words, it can be concluded that the speed of adjustment is good for M1 and decent for M2 money demand.

To examine the stability of monetary models, we use CUSUMQ or CUSUM test. The test method is based on a recursive regressions by OLS approach. The hypothesis would be:

$\mathrm{H}_{0}$ : Stability of coefficients

$\mathrm{H}_{1}$ : Instability of coefficients

If the test statistic that is the Cumulative Sum of Recursive Residuals (CUSUM) between two straight lines (the area between the two crisis lines) be at $5 \%$ level, the null hypothesis cannot be ruled out and the long-term relationship will be stable. The CUSUMSQ test uses the Cumulative Sum of squares of Recursive Residuals.

In relation to the stability test of M1 money demand, the first test statistic path shows that there is instability at the end of the period in 2006. Based on the second test, M1 money demand passed from the instability boundary to some extent and shows volatility in 1999-2000. The results of two tests have shown in Diagrams 1 and 2 .

Test of parameter stability have shown that M2 money demand function is stable in first case (CUSUM test). However, it should also be considered that the end of the period, it approaches the unstable boundary. Based on the second test in 
2008-2009, it passed from the instability boundary and shows volatility. However, after a while placed on stable path until stability is achieved. The results have shown in Diagrams 3 and 4. In comparison between M1 and M2 money demand stability can be conducted that M2 money demand is more stable than M1. As such, it could be a reason for considering more monetary assets on M2.

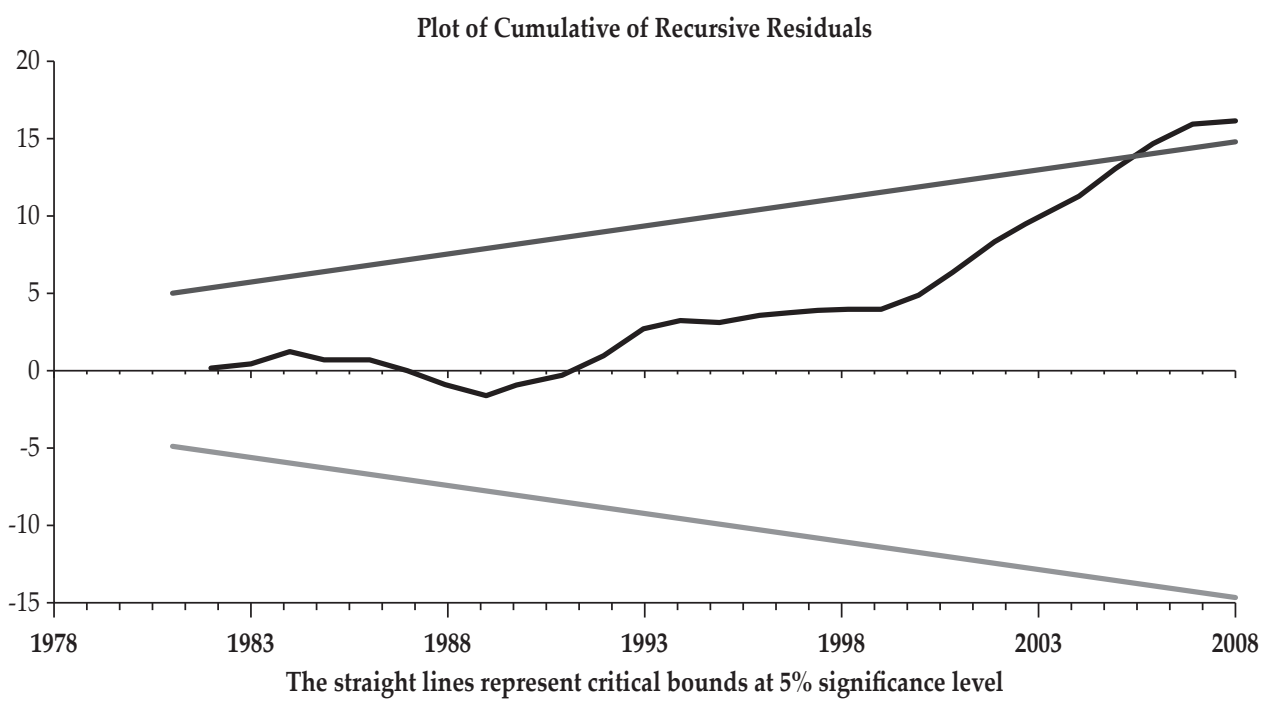

Figure 1a. Results of CUSUM Test for M1 Money Demand

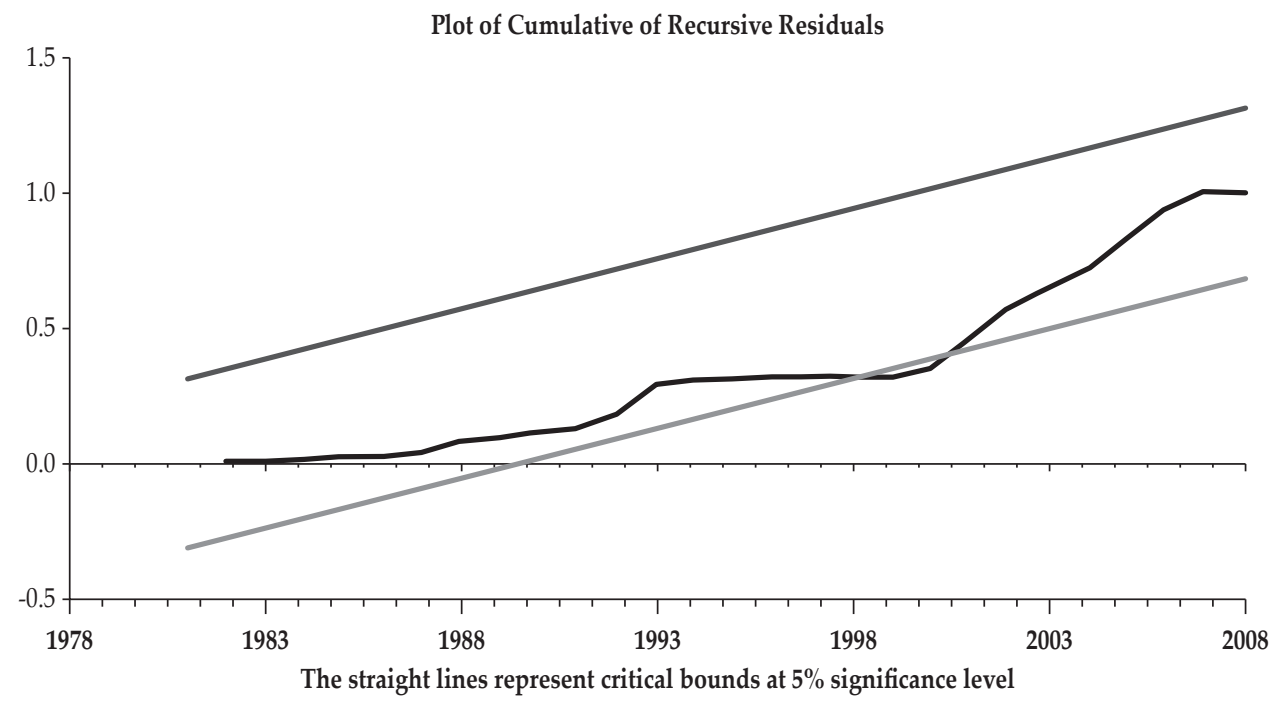

Figure 1b. Results of CUSUMSQ Test for M1 Money Demand 


\section{CONCLUSION}

As mentioned, money demand models in Islamic economics were always raised based on the theories of classical macroeconomics, and there have not been many studies seeking to explain the money demand in Islamic economics based on the approach of modern macroeconomics. As it became clear, in the new approach to macroeconomic, micro foundation of macroeconomics has always been considered.

For this reason, money demand function must be achieved based on the demand function extraction models in in microeconomics. Accordingly, economists used different patterns and approaches to achieve this matter. This research, while reviewing all these patterns, has discussed and examined strengths and weaknesses of each of these models based on Islamic principles, and have chosen the shopping time pattern as the closest model to Islamic economy. Then, it changed its constraint based on Islamic principles, in that it extracts money demand function from the Islamic viewpoint, on the basis of micro foundation. By solving this model based on Islamic constraints, it was determined that money demand in Islamic economy has a relationship with income and rental rates of sukuk. In addition, by solving equations of the model, it was determined that the marginal product of capital, caused by spending an additional unit of income to charity, depends on the expected inflation rate, the rate of depreciation, and rental rates of sukuk.

In order to investigate the long-run relationship among the variables in the models, we employed ARDL approach. The results of Short-run estimation of M1 and M2 money demand confirmed the existence of the long-run equilibrium relationship among the variables of the two models. M1 and M2 money demand is highly co-integrated with the logarithm of real GDP and rental rate of Sukuk. Using CUSUMQ or CUSUM test, conducted that M2 money demand is more stable than M1, which could be a cause of considering more monetary assets on M2.

Accordingly, the empirical result from Iran proves the stability of our Islamic money demand function. Therefore, our Islamic money demand function based on new money demand function with micro foundation is suitable for explanation of demand for money in Islamic economy.

\section{REFERENCES}

Apergis N., Karpetis, C., Kotsiopolu, A. Mitakidou, E. \& Tsiakiri, T. (1999). The Demand for Money in Greece: Evidence Through a Shopping Time Technology Model and Cointegration. SPOUDAI-Journal of Economics and Business, 49(1-4), 33-45.

Barata, J. Martin. (2001). Demand for Money as a Financial Asset- Theory and Evidence. European Review of Economics and Finance, 1.

Bawa, S., \& Kaur, G. (2010). Stability of Demand for Money Function by Business Firms in India. IUP Journal of Monetary Economics, 8(4).

Esmaili, F., Sadr, S., Noferesti, M. (2012). Money Demand in an Interest Free Economy. Journal of Economic Research (Tahghighat- E- Eghtesadi), 47(1), 129-151. DOI: 10.22059/JTE.2012.24676

Ezzati, M. (2003). The Effect of Religious Faith as a Muslim Consumer Behavior. Journal of Islamic Economy, 11. 
Handa, J. (2009). Monetary Economics (Second edition). Routledge.

Hosseini, R. (2000). Muslim Model of Allocating Income and Consumer Behavior. Qom: Islamic Institute of Culture and Thought.

Iravani, J. (2012). The Correct Consumption from the View of Islam. Mashhad: Razavi University.

Judd, J. P., \& Scadding, J. L. (1982). The Search for a Stable Money Demand Function: A Survey of the Post-1973 Literature. Journal of Economic Literature, 20(3), 9931023.

Latif, B. (1990). The Foundation of Money Demand in Islamic Economics. Journal of Human Science. Tehran.

Ljungqvist, L., Sargent J.T. (2000). Recursive Macroeconomic Theory (Second edition). Massachusetts Institute of Technology.

MacCallum, C. (1989). Monetary Economics Theory and Policy. Macmillan Publishing Company. New York.

Mir Moezi, H. (2003). Money Demand in Islamic Economy. Journal of Islamic Economy, 10, Qom.

Mir Moezi, H. (2005). Macroeconomics through Islamic Approach. Islamic Institute of Culture and Thought, Qom.

Moradi, M. (2000). Money Demand Based on Microeconomics in No Interest Economy. Journal of Budget and Management, 58. Tehran.

Svensson, L., \& Williams, N. (2005). Monetary Policy with Model Uncertainty: Distribution Forecast Targeting (No. w11733). National Bureau of Economic Research.

Walsh E. Carl. (2010). Monetary Theory and Policy (Third Edition). MIT Press. 
This page is intentionally left blank 